\title{
Proposal of a Learning Styles Identification Tool for Sakai Virtual Learning Environment
}

\author{
Paulo Alves ${ }^{1, *}$, Luís a Miranda $^{1}$, Carlos Morais ${ }^{1,2}$, Evandro Alves ${ }^{1}$ \\ ${ }^{1}$ Instituto Politécnico de Bragança, Bragança, 5300-254, Portugal \\ ${ }^{2}$ CIEC,Universidade do Minho, Braga, 4710-057, Portugal
}

\begin{abstract}
W e$ are living in an essentially technological world, in which technology facilitates and promotes the development of institutions and the people who work or study in these institutions. Thus, it is claimed that technology should increasingly meet people's needs according to their goals, interests and learning styles. Aiming to improve the teaching and learning process, and based on a perspective of adaptation of the learning environment to the learner's needs, we present, in this article, the integration of learning styles in learning management systems by integrating the Honey-Alonso Learning Styles Questionnaire (CHAEA) in Sakai collaborative learning environment, which was adopted in a higher education institution.
\end{abstract}

Keywords Virtual Learning Environments, Sakai, Learning Styles

\section{Introduction}

Bearing in mind the influence of information and communication technologies (ICT) in teaching and learning, learning management systems have a special role in providing the necessary conditions so that their users can select the resource materials and technology that best meets their needs. Therefore, the introduction of tools which enable users' learning styles identification can be a good contribution to the improvement of learning managing systems adaptability to their users' needs.

The aim of this article is to support and present the introduction of a module in the Sakai environment used in the higher education institution of the authors of this study. This module consists of the Honey-Alonso Learning Styles Questionnaire (CHAEA). Apart from setting the theoretical background of learning styles and learning management systems, we analyze the presented module based on some examples of the module usage in the Sakai environment, and we present some conclusions.

Results from a study developed by Graf, Liu and Kinshuk[1] reinforce the belief that students with different learning styles behave differently in online courses, including when browsing through learning objects and when carrying out activities. These differences represent challenges for the design and development of learning management systems, as they must seek to ensure their

* Corresponding author:

palves@ipb.pt (Paulo Alves)

Published online at http://journal.sapub.org/computer

Copyright (C) 2012 Scientific \& Academic Publishing. All Rights Reserved adaptability to the users' needs, bearing in mind their learning styles. This leads to the need of integrating resources which enable users' learning style identification in the learning environment.

The identification of learning styles helps students to be aware of the way they learn, thus enabling them to make independent decisions, and allowing them to consciously enhance their learning, especially as far as the choice of paths, time and topics are concerned[2].

Given the current world's rapid technological evolution, and the existence of a society which is increasingly competitive and uncertain about the future, it becomes essential to consider the student as the center of their own responsibilities in the selection of their life choices and the ways they want to go. Therefore, providing students with tools which will enable them to get to know themselves better, as well as the educational community they are in, represents a challenge which the combination of learning styles theories with the potential of learning management platforms can help overcome.

Gallego and Alonso[3] suggest that the application of technologies, including multimedia and the Internet, is for individual use, and that, therefore, it is important that it is adapted to the student's learning style. Also, they claim that the absence of this adaptation may cause the learning not to have the desired pace nor effectiveness.

The main purpose of the teaching and learning process is to get students to learn. However, the knowledge which is to be acquired by students admits several dimensions and levels of depth. The understanding of these various dimensions and levels of depth may depend, among other things, on the physical and technological conditions of the educational 
institutions; the scientific and technological competence of their professionals; the teaching strategies used; and the students' learning styles.

Graf, Liu and Kinshuk[1] suggest that the knowledge of students' learning styles can facilitate the selection and construction of the most suitable resources to be used in the teaching and learning process, as well as the selection and creation of activities and performance sequences which can meet each student's interests and ways of learning. Also, these authors claim that it is essential that the both the order of priority of the activities to be developed and the resources used should take into account the learning styles of the students to whom they are intended.

According to Klasnja-Milicevic, Vesin, Ivanovi and Budimac[4], personalized learning occurs when the e-learning systems deliberately provide the projection of educational experiences which meet students' needs, goals, talents and interests. In the context of learning, we must bear in mind that students can have different individual needs and characteristics and, therefore, cannot be treated uniformly.

Given the importance of the identification of learning styles in the teaching and learning process, we present, in this paper, the integration of the Honey-Alonso Learning Styles Questionnaire (CHAEA) in the Sakai platform of a higher education institution.

Easy access to a learning styles questionnaire in the e-learn ing platform that students and teachers regularly use may enable their learning styles identification, allowing the teaching and learning process to be oriented according to the students' interests and learning styles.

Furthermore, besides the benefits that the availability of the CHAEA questionnaire in the Sakai learning management system may bring to teachers and students, it also enables the storage of information that can be useful in providing starting points for new research involving learning styles.

\section{Students' Learning Styles}

People learn differently, depending, among other things, on where they live, their culture and their motivation. Each person has particular preferences concerning the learning environment, the methods they use and the structuring level adopted, i.e. people have different learning styles[3]. The influence of individual style in learning is also recognized by Chacon[5] when he questions the fact that students with the same cultural level, motivation, age and gender learn in different ways.

Defining the concept of learning style is a difficult task, as in each culture there are set rules which influence life and the development of a large number of standardized attitudes, causing individual styles to fade in the face of collective purposes. However, there are individual specificities which constitute a person's identity, distinguishing them from others and making many of their actions and reactions predictable. We can consider such specificities as indicators of their learn ing styles.
According to Keefe, cited by Alonso, Gallego and Honey[6], learning styles are indicators of cognitive, affective and physiological aspects which can be used as relatively stable indicators of how learners perceive, interact and respond to their learning environments.

Emphasis on the theory of learning styles is enhanced by Graf, Kinshuk and Liu[7], who suggest that knowledge of the students' learn ing styles can help improve learning and teaching in many different ways, and is important for teachers as they may benefit from knowing how their students learn and from having a deeper understanding of their students. This can help them to explain the contents in a more interesting way or to prepare the learning material more adequately. Also, the identification of learning styles allows students to become awa re of their individual strengths and weaknesses and to benefit from the combination of the teacher's teaching style with the student's learning style.

Honey and Mumford[8] consider four learning styles: active, reflective, theoretical and prag matic.

Alonso, Honey and Galego[6] point out some people's key characteristics in association with each learning style as follows: active style - uplifting, imp roviser, discoverer, daring and spontaneous; reflective style - thoughtful, conscientious, receptive, analytical and comprehensive; theoretical style - methodical, logical, objective, critical and structured; pragmatic style - experimenter, practical, direct, effective and realistic.

The identification of styles allows each person to become aware of their strengths and weaknesses, and to facilitate cooperation and collaboration in educational settings.

Knowing students' learning styles helps to uncover learning patterns, enabling the use of teaching and learning strategies which are primarily oriented to students as they really are, instead of idealized and abstract ones, thus promoting a personalized learning.

When we take into account students' learning styles diversity, and when teaching is oriented based on this fact, students can become more responsible, and learning can be more effective[9]. The identification of learning styles is important because it allows the connection between education and the ways students learn, thus enabling the appearance of better results and more willingness to learn[10].

Students' individual differences play a central role in on-site learning as well as in education supported by learning management systems. Each student has their own individual needs and characteristics, such as different motivation, prior knowledge, cognitive abilities and learning styles[1]. Based on a study that evaluated students' browsing behavior in an online course, the authors concluded that there are differences in students' browsing behavior depending on their learn ing styles, and that this should be considered when constructing browsing models and learning objects so that they adapt to the main style of each student.

Knowing students' learning styles can help improve learning and teaching in many ways. Teachers can benefit from this knowledge to prepare the material for learning 
activities that suit the students' preferred learning ways, making students' learning easier and more attractive. Students who are aware of their learning styles and individual strengths and weaknesses can better understand why learning is sometimes difficult for them and thus, seek to develop their potential in order to overcome their weaknesses.

Gallego and Alonso[3] note that many studies have demonstrated the diversity and relativity of learning. Many people organize their thoughts in a linear, sequential way, while others prefer holistic approaches. The differences in the way of thinking have implications for time management, environment physical organization, daily planning, and for the way in which change and the prospects for the future are faced. Also, cognitive research has shown that people think, capture, process, store and retrieve information differently. The learning styles theory confirms the existence of diversity among individuals, and proposes a way to improve learning through personal reflection and bearing in mind the differences in the way of learning.

The theory of styles is not intended to measure the style of each individual in order to label them according to the prevailing style. It aims to identify what is necessary to develop in each individual in order to improve aspects related to styles that are less developed[11].

The theory of styles deserves special attention from academic institutions. In this regard, Akkoyunlu and Soylu[12] based on their study to support the theory of learning styles, arguing that it is important for academic institutions which are interested in online courses, as understanding the differences among students' learning styles can help to create flexible teaching strategies that will improve e-learning environments. The same authors consider that when the diversity of learning styles is understood, it can be translated into appropriate learning environments that allow students to achieve success.

\section{Learning Management Systems}

A learning management system, also called e-learning platform, consists of one or more computer applications which provide a means to deliver, manage and monitor educational activities and training both in on-site and distance learning. According to Ellis[13], an e-learning platform should address the following requirements:

- Provide and gather contents for teaching;

- Centralize and automate administration;

- Use its own services;

- Consolidate training initiatives on a perspective of scalability;

- Support portability and standards commonly accepted;

- Provide personalized contents and allow their reuse.

The technology platforms which support virtual learning environments have earned special interest of the governing bodies of higher education institutions due to the central role they assume in managing the process of teaching, learning and research. These platforms admit several names, such as learning management systems, virtual learn ing environ ments, collaborative learn ing environments and course management systems.

Caldeira[14] defines learning management systems as applications which distribute interactive media, establish channels of synchronous and asynchronous communication, manage the learning process and enable the participation of students and teachers, all this in an integrated way. In the establishment of communication channels, the tools used, such as electronic mail, chat, discussion forums, among others, facilitate communication between students, teachers and the institution, using textual information, audio and video conferencing.

Collaborative learning environments are critical in changing a paradigm of teaching and learning characterized by low collaboration and spatial and temporal constraints into a paradigm that can be based on collaboration and cooperation, without space or time limitations.

\subsection{The Sakai Collaborative Learning Environment}

The process of implementing a learning management platform is considered complex due to the necessity to meet a set of requirements of the institution, along with teachers, students and platform administrators' expectations.

It has been estimated that today there are more than 250 providers of co mmercial Learning Management Systems. In addition, over 40 open source LMS offerings have recently been identified (some of the most well-known are Moodle, ILIAS, eduplone, Claroline and Sakai). In order to ensure that both short and long term users have access to the best applications available, these Open Source software applications have been built upon open standards [15].

Initially, besides the various solutions in the market, which can be commercial or open-source, several learning management systems were internally developed in the higher education institution to which this implementation refers to. These systems took into account the requirements of each of the colleges that make part of the institution. Besides these, two different open-source platforms were adopted, from which Moodle stood out with more expression.

However, the use of multiple platforms led to great difficult ies concerning support, compatibility and integration of various services of the institution. Due to the specific ities of each platform, it was impossible to have an aggregated view of the whole institution.

In order to overcome the referred problems, the decision was made to use the Sakai collaborative environment for the entire institution, which supports teaching, learning, and research, both in on-site and distance contexts.

Thus, since 2007, the institution has only used the Sakai collaborative learning environment, which we will designate as Sakai. Sakai is a project developed by a worldwide consortium of higher education institutions whose main objectives are to develop and share collaborative tools that support teaching, learning and research. 
The Sakai Project began in 2004 through a consortium of several universities: University of Michigan, Indiana University, MIT, Stanford, uPortal Consortiumand the Open Knowledge In itiative (OKI), and aimed to develop a set of collaborative tools for teachers, students and researchers which would support teaching and research. It is an open-source project that aims the sharing of applications among higher education institutions [16].

Within the universe of learning management systems, Sakai has gained a great reputation because it was designed specifically for higher education and includes a very wide community.

As Gray[17] points out, the educational community is interested in providing students with conditions which allow them to make their learning results known through the creation of content in learning platforms. The creation of contents in platforms based on the Web by the students themselves involves students' commitment in the development of various skills, thus increasing their critical and creative ability, and it also enables them to participate and receive their colleagues' contribution in the review of their productions.

The main tools provided by Sakai collaborative environment are as follows: Notices, Reviews / Assignments, Calendar, Chat, Drop Box, Email, Forums, Register, Messages, News, Reviews, Presentations, Resources, Programs, On line Tests and Quizzes, Web Content, Wikis and Blogs.

Sakai can hold a variety of teaching strategies. For example, blended learning could make use of tools such as Resources, Discussion Forums, Online Tests \& Quizzes, Assignments, Surveys, among others. An online teaching strategy could make use of tools which include a Lesson Design Tool, Tests and Assignments, Discussion Forums, Online Meeting Tools, Surveys, among others. In collaborative learning, the available tools include Wikis, Blogs, Discussion Forums, Tests \& Quizzes, Assignments, Chat, Drop Box, Surveys, Email, Archive, among others [18].

Sakai uses a modular architecture based on Java (J2EE) and is service-oriented, allowing easy integration in organizational portfolio application. It consists of tools, components, services and a framework. Its major advantage is the integration of the services of the higher education institution in which it is used, including academic services (register, exams, and timetables), and human and financial resources, with local adaptations of great durability concerning new versions of the platform.

Apart from the e-learning component and the features aimed at the creation of portfolios, the Sakai platform holds any kind of activity requiring collaborative work with in the institutions.

A collaboration system such as Sakai enables people to develop projects or subprojects, interact and work together as a distributed team[19].

Considering the Sakai co llaborative learning environment as a community, we can consider that it consists of four key points: adoption, contribution, sharing and support. This sense of mutual aid has been a major factor in the continuous growth of the community, as more and more education institutions and companies are adopting the platform.

The platform development is conducted by the Sakai community, but the Sakai foundation is responsible for the definition of the development guidelines. This foundation has a board of directors and a group of staff members who are directly supported by the foundation. These can be educational organizations and nonprofit or noncommercial organizations.

Sakai initially appeared as a single product (Collaboration and Learning Environment - CLE), which intended to implement a collaborative learning environment and ended up incorporating an open-source portfolio (OSP). This product is more aimed at e-learning, and includes a core of services which support a set of external tools, each one with a specific function.

As a result of the constant rethinking of the Sakai platform, a new platform (Open Academic Environment - OAE) was developed. This product is more oriented towards shared and collaborative learning, focusing on students, their peers and teachers, with an emphasis on the social aspects. This platform is still in an embryonic phase, and it is only possible to use it in a hybrid form, in combination with CLE. This combination provides a platform which includes very interesting features but which still requires a high maintenance cost as well as teachers' training.

\subsection{Tool Development for S akai Collabor ative Learning Environment}

The development of tools for Sakai co llaborative learning environment is always possible because the code is open source. Publishing and sharing a new tool in Sakai collaborative environment starts with the announcement of the intention to develop a new tool and the creation of a space in the project version management system service, as well as a space in the documentation "Confluence " server. A tool will become official and will be distributed together with the platform if it is considered mature, useful and has the potential to be widened to other institutions.

For the development of tools for the platform it is necessary to know the available Sakai framework, i.e. the services that the Sakai collaborative environment provides for the creation of tools. Thus, Sakai can be viewed as a two-layer application: the inner layer, which is made of the support services (called kernel), and the external layer, in which the components which produce the features available to users are.

After knowing the framework, it is necessary to know how to configure it for the intended environment and for the environment in which the final product will go into production. Apart from the persistence (database, files) and integration, with directory services and email, Sakai includes a wide range of integration options which enable its easy adaptation to almost any scenario. However, more detailed situations may require modification or parts extension of the 
kernel, such as the integration of academic services, which are particularly oriented towards academic management, i.e. applications, certificates and students' personal data. In the Sakai community documentation, this service is called Student Information System(SIS).

As far as implementation tools are concerned, there are two possible scenarios: the development of tools for an existing facility or the development of tools and extended functionality for a new facility. The second scenario will be the one approached here, as it is the most relevant to the institution under analysis as well as to those willing to adapt the Sakai collaborative environment to their needs. The difference between this and the first scenario is the fact that it only needs the time dependencies of source code compilation, and management is made by Maven. The versions used in the development of the tool are JDK1.6-u26, and 5.5.31 To mcat Sakai-2.7.1 (Kernel 1.1.x).

In order to create a new tool for Sakai, we can create the whole structure of directories and configuration files (Spring, Hibernate, etc.) on one directory created within the code downloaded from Sakai though this is a lengthy process. Nonetheless, there are tools assisting in the creation of a new tool, because although only one time is required for each new tool we choose to implement, these tools help us implement the best practices. Therefore, the options are as follows:

- Sakai App Builder - this is a plug-in for the Eclipse development environment with support for RSF, JSP, JSF and Wicket with several options for creating a new project, developed by Aaron Zeckoski;

- W icket Sakai Maven Archetype - a Maven archetype (Maven toolkit for generating project) with layers of persistence, business and presentation with Spring, Hibernate and Wicket, developed by Steve Swinsburg.

A Sakai tool should be organized in three typical layers: data persistence layer, business or logic layer and presentation layer.

The three areas (Shared, Webapps, Components) are directories in Tomcat server. The blocks are the components in which the tool can be split. The API (Java interfaces) and the data model (Java classes that represent tables with Hibernate) are packaged in a JAR file and placed on the board shared in Tomcat. The code that implements the interfaces (both the data persistence layer and the business layer), as well as configuration files and Spring Hibernate (or other), are placed in the components directory of the Tomcat server with the particularity that the whole code is added in libraries on JAR files. Classes and other files responsible for building the user interface are packaged in a WAR file and copied to the webapps Tomcat server directory.

\section{Module for Learning Styles Identification}

Based on the cornerstone principle that the identification of learning styles can provide a better individual knowledge of students and facilitate the teachers' work in developing strategies that meet the learning styles, we decided to develop a new tool for the Sakai collaborative environment to identify the students' learning styles.

Once we decided to introduce a questionnaire of learning styles, some questions arose:

- Which of the learning styles questionnaires should we choose?

-What are the technological resources involved?

-Who can fill in the questionnaire?

- How to present the results?

-Who can access the results?

- What feedback can each user have after filling in the questionnaire?

- How to integrate the questionnaire with the other tools of the Sakai collaborative environ ment?

Given the importance of identifying learning styles and the fact that the Sakai collaborative environment does not have any tool that allows identificat ion of students'styles, we chose to integrate in the Sakai platform of the institution the Learning Styles Questionnaire CHAEA, written by Catalina Alonso and Peter Honey and adapted to the Portuguese language by Luisa Miranda and Carlos Morais[20].

This instrument cons is ts of 80 questions which assess each subject on four learning styles: active, theoretical, reflective and pragmatic. Each style allows a score which can range from a minimu m value (ze ro points) to a maximu m value (20 points) and the classification of each style includes five levels, resulting in the classification of each subject according to their score. The levels for each style are very high, high, moderate, low and very low.

This questionnaire was validated with a sample of 1371 students from 25 schools from the university Co mp lutense of Madrid, in a study conducted by professors Catalina Alonso Gallego and Domingo Gallego of the Universidad Nacional de Educación a Distancia in Spain (UNED) and has been used in several academic studies, including Miranda[21], Dourado, Leite and Soares [22].

Therefore, and because we support a self-learning approach as well as a teaching centered on the interests of the student, we believe it is useful and essential to provide students and teachers who regularly use the collaborative environment Sakai with a survey of learning styles, so that each user can know themselves better and thus improve their skills taking into account their predo minant learning styles.

Providing personalized support and adaptive characteristics which bear in mind students' learning styles has a high potential that makes learning easier for students, as it reduces their efforts to learn and increases their performance[1]

This module allows students' learning styles identification and may, therefore, help teachers define teaching and learning strategies when implementing the development of curriculum units. This tool was developed with Spring IoC, Hibernate and Apache Wicket, and consists of two components: a questionnaire completion component and an administration component. 


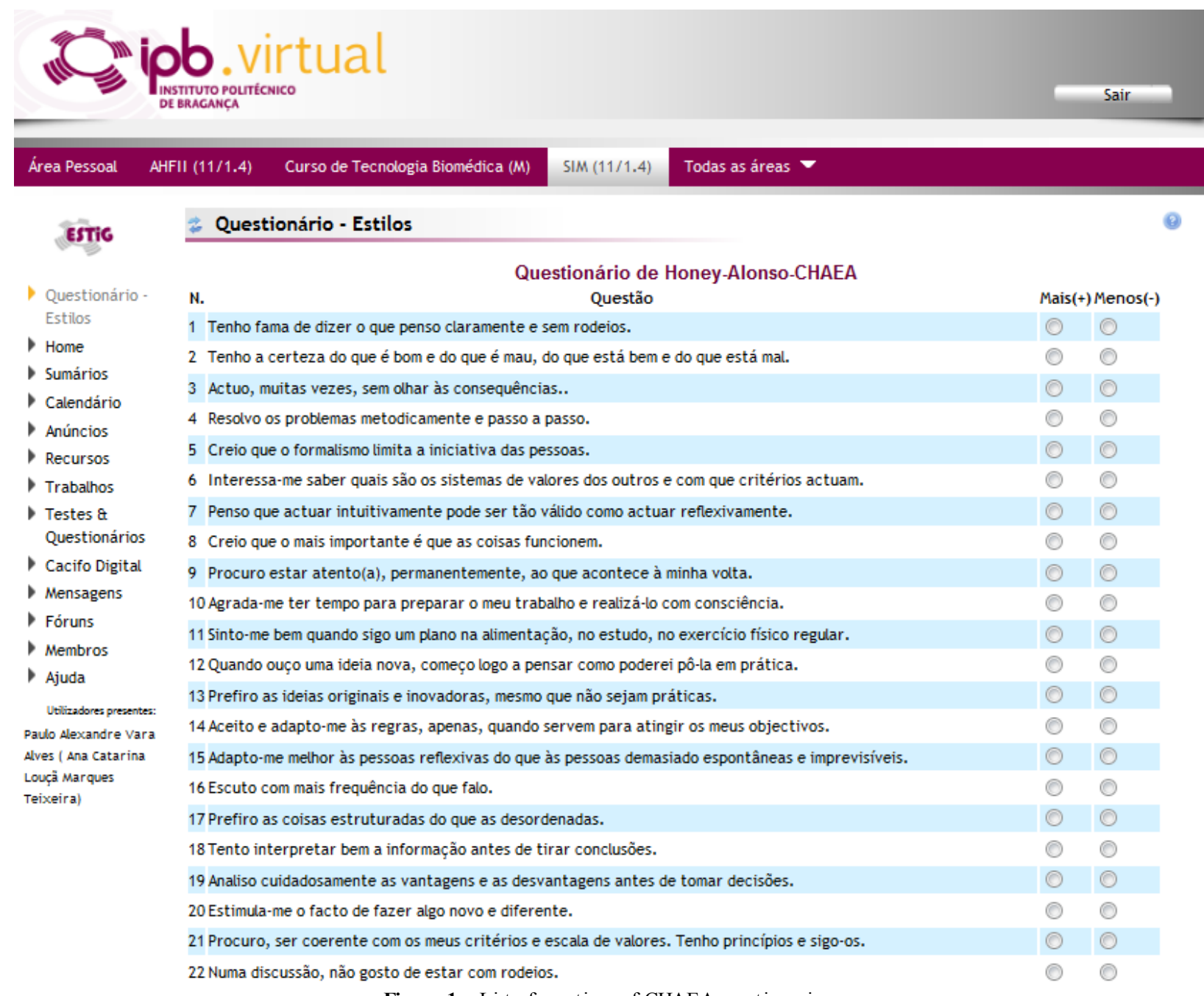

Figure 1. List of questions of CHAEA questionnaire

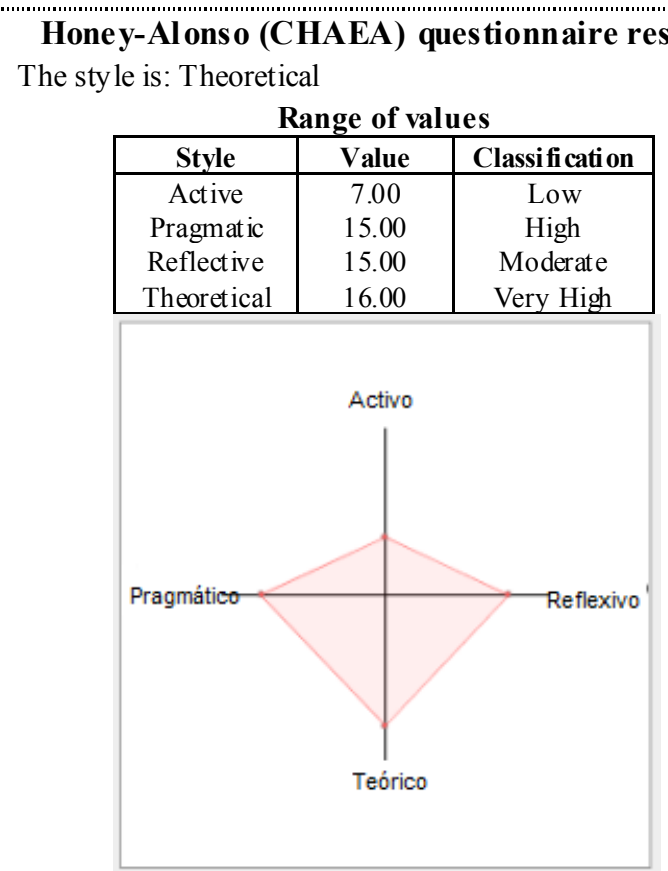

Figure 2. Results of the questionnaire presented to the student
The questionnaire completion component gives the student the information that there is a questionnaire to fill in whenever there is an active questionnaire, and it presents a link to start its completion. Before presenting the 80 questions for identifying learning styles, it presents the completion instructions to students, which indicate the purpose of the questionnaire, the average completion time and the kind of answers.

In order to better understand the integration of the questionnaire in Sakai collaborative environment, we present the beginning of the questionnaire in Figure 1.

After the questionnaire has been submitted, the dominant learning style is presented to the student, as well as the level of preference for each style on a scale of 0 to 20 points, and the main characteristics as sociated with each style.

Figure 2 shows the feedback received by each student, after completing CHAEA questionnaire.

The tool automatically distinguishes the teachers' profile by giving them access to the administration component. Through the administration area, the teacher can make the CHAEA questionnaire available to students. When there are responses to the questionnaire, the teacher can see both the individual results and the average results of a group of 
students. This data can be exported to a spreadsheet in Microsoft Excel format.

This module identifies which of the Sakai tools are commonly used, depending on the learning style, allowing the assessment of the relationship between learning styles and the tools used (Figure 3)

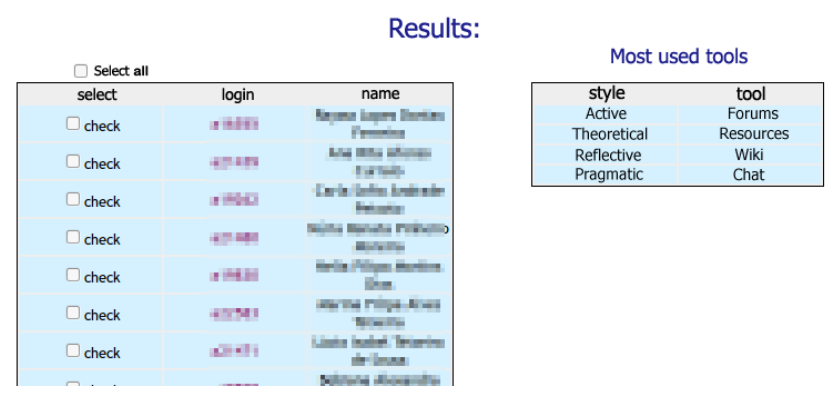

Figure 3. Relationship bet ween learning styles and tools used

For each learning style the module counts the number of access es to each Sakai tool, showing the most used tool.

The CHA EA questionnaire tool is in a pilot phase in Sakai platform and has been tested in three license degree course units and four master degree course units, with 137 responses to the questionnaire, in a total of 311 students enrolled in the courses where the module was tested, thus representing a sample of $44 \%$.

The data obtained from the responses of the 137 students was computed and the mean scores obtained in each style are shown in Table 1.

Table 1. Average score for each learning style

\begin{tabular}{|c|c|c|c|}
\hline Active & Pragmatic & Reflective & Theoretical \\
\hline 8.5 & 9.7 & 10.6 & 9.3 \\
\hline
\end{tabular}

By analyzing the table we can see that there are no relevant differences between scores in each style, as the scores range from 8.5 points in the active style to 10.6 points in the reflective style. The reflective style is prevalent in the majority of students.

In order to establish students' preference levels in each style, we used a table of correspondence between the scores obtained in each style and a table of preferences defined by Miranda[20], which includes the levels very high, high, moderate, low and very low.

Although no study has been conducted on the level of acceptance of the CHAEA questionnaire, the high percentage of responses enables to conclude that in the future, the questionnaire will be well accepted by the students of the institution under analys is.

\section{Conclusions}

The use of a Sakai collaborative environment in the institution where the study was conducted is an important asset for teachers and students, especially in the areas of academic management, content management and student ass essment.

The Sakai platform standard tools have satisfied the requirements laid down in their implementation, however, the challenge is to improve the platform in order to respond to new educational requirements, such as enabling each student to know their learning style, and making it possible for teachers to know their students' learning styles.

With the integration of the questionnaire for learning styles in Sakai collaborative environment, each member of the institution has now a tool which can help them improve their performance by showing the aspects which are to be maintained or improved according to their learning preferences.

Although studies related to learning styles are still controversial for some authors, such as Aragon et al[23] and Coffield et a1.[24], there are other authors, like Gallego and Alonso[3], who argue that the learning styles are essential to improve the learning process.

\section{REFERENCES}

[1] S. Graf, T. Liu, Kinshuk, "Analy sis of learners' navigational behaviour and their learning styles in an online course", Journal of Computer Assisted Learning, pp. 116-131, 2010

[2] R. Leonila, "Estilos de Aprendizaje de los Estudiantes, en las Unidades Academicas de Enfermaria de la Universidad Autonoma de Guerrero", IV Congreso Mundial de Estilos de Aprendizaje, J. Cué, J. Rineón, e M. Velázques Editors, pp. 262-270, México, 2010

[3] D. Gallego, C. Alonso, "Estilos de Aprendizaje", IV Congreso Mundial de Estilos de Aprendizaje, J. Cué, J. Rineón, e M. Velázques Editors, pp. 24-48, México, 2010

[4] A. Klasnja-Milicevic, S. Cevi, B. Vesin, M. Ivanovi, Z. Budimac, "E-Learning personalization based on hybrid recommendation strategy and learning style identification", Computers \& Education, n. 56, pp. 885-899, Elsevier, 2011

[5] L. Chacón, "Influência del Estilo de Pensamiento en la construcción de Mapas conceptuales", Proc. of the Second Int. Conference on Concept Mapping, A. J. Cañas, J. D. Novak, Eds., San José, Costa Rica, 2006

[6] C. Alonso, D. Gallego, P. Honey, "Los estilos de aprendizage: Procedimientos de diagnóstico y mejora", 4th ed., Bilbao: Edicion es Mensajero, 1999

[7] Graf, S., Kinshuk, \& Liu, T.-C. "Supporting Teachers in Identifying Students' Learning Styles in Learning Management Systems: An Automatic Student Modelling Approach". Educational Technology \& Society, 12 (4), 3-14, 2009

[8] P. Honey, A. Mumford, "The manual of learning styles". Maidenhead: Peter Honey, 1992

[9] T. Bender, "Discussion-based online teaching to enhance student learning: Theory, practice and assessment". Sterling, Virginia: Stylus Publishing, LLC, 2003

[10] B. Given, "The overlap between brain research and research 
on learning style". In Steven J. Armstrong et al. (Eds.) Learning Styles: Realibility \& Validity, Proceedings of the 7th Annual ELSIN Conference, pp. 173-178, Ghent, 2002

[11] D. Barros, C. Garcia, S. Amaral, "Estilo de Uso do Espaço Virtual", Revista de Estilos de Aprendizagem, nº1, vol 1, pp. 88-108, 2008

[12] Akkoyunlu, B., \& Soylu, M. Y. “A Study of Student's Perceptions in a Blended Learning Environment Based on Different Learning Styles". Educational Technology \& Society, 11 (1), 183-193., 2008

[13] R. Ellis, "Field Guide to Learning Management Systems", ASTD Learning Circuits, 2009

[14] T. Caldeira, "Plataformas de e-learning no actual contexto de Bolonha", A groforum, 2010

[15] Kumaran, K. S., \& Nair, V. M. "Future trends in E-Learning". Distance Learning and Education (ICDLE), 2010 4th International Conference on, pp 170 -173, 2010

[16] Sakai Project, http://sakaiproject.org, 2012.

[17] Gray, K. "Students as Web 2.0 authors: Implications for assessment design and conduct". Australasian Journal of Educational Technology, vol. 26, $\mathrm{n}^{\mathrm{o}}$ 1, pp. 105-122, 2010

[18] Li, J., \& Wang, X. "Study the use of Sakai in distance education". Educational and Information Technology (ICEIT), 2010 International Conference on (Vol. 3, pp V3-167 -V3-170), 2010
[19] C. Severence, G. Golden, R. Crouchley, A. Fish, T. Finholt, B. Kirschner, J. Eng, R. Allan, "Using the Sakai collaborative toolkit in e-Research applications", John Wiley \& Sons, Ltd, 2007

[20] L. Miranda, C. Morais, "Estilos de aprendizagem: o questionário CHAEA adaptado para língua portuguesa", Revista de Estilos de Aprendizagem, ${ }^{\circ} 1$, vol 1, pp. 66-87, 2008

[21] L. Miranda, "Educação online: interacção e estilos de aprendizagem de alunos do ensino superior numa plataforma web", tese de doutoramento, Universidade do Minho, 2005

[22] L. Dourado, L. Leite, F. Soares, "Learning Styles of students attending a 1st cycle leading to a degree in Education", In M. H. Pedrosa-de-Jesus, C. Evans, Z. Charlesworth \& E. Cools (Eds.). ELSIN XV - Proceedings of the 15th Annual Conference of the European Learning Styles Information Network. Aveiro: Department of Education, University of Aveiro, pp. 168-174., 2010

[23] S. Aragon, S. Johnson, N. Shaik, "The Influence of Learning Style Preferences on Student Success in Online Versus Face-to-Face Environments", American Journal of Distance Education, Vol. 16, Iss. 4, 2010

[24] F. Coffield, D. Moseley, E, Hall, K. Ecclestone, "Learning styles and pedagogy in post-16 learning: a systematic and critical review", LSRC reference, Learning \& Skills Research Centre, London, http://www.hull.ac.uk/php/edskas /learning\%20styles.pdf, 2004 